\title{
On the Persistence of Cold-Season SST Anomalies Associated with the Annular Modes
}

\author{
LAURA M. CiAsto \\ Climate Change Research Centre, University of New South Wales, Sydney, New South Wales, Australia \\ Michael A. Alexander \\ NOAA/Earth System Research Laboratory, Boulder, Colorado \\ Clara Deser \\ Climate and Global Dynamics Division, National Center for Atmospheric Research, ${ }^{*}$ Boulder, Colorado \\ MATTHEW H. ENGLAND \\ Climate Change Research Centre, University of New South Wales, Sydney, New South Wales, Australia
}

(Manuscript received 20 November 2009, in final form 16 September 2010)

\begin{abstract}
In this study, a simple stochastic climate model is used to examine the impact of the ocean mixed layer depth, surface turbulent energy fluxes, and Ekman currents on the persistence of cold-season extratropical sea surface temperature (SST) anomalies associated with variability in the annular modes of atmospheric circulation in both hemispheres. Observational analysis reveals that during the cold season, SST anomalies associated with the southern annular mode $\left(\mathrm{SST}_{\mathrm{SAM}}\right)$ persist considerably longer than those associated with the northern annular mode (SST $\mathrm{NAM}$ ). Using the simple model, it is shown that the persistence of the cold-season $\mathrm{SST}_{\mathrm{SAM}}$ is consistent with the simple stochastic climate paradigm in which the atmospheric forcing is approximated as white noise, and the persistence of SST anomalies can be largely determined by the thermal inertia of the ocean mixed layer. In the North Atlantic, however, the simple climate model overestimates the persistence of the cold-season $\mathrm{SST}_{\mathrm{NAM}}$. It is thought that this overestimate occurs because the NAM-related heat flux forcing cannot be described purely as white noise but must also include a feedback from the underlying SST anomalies.
\end{abstract}

\section{Introduction}

Sea surface temperatures (SSTs) play a crucial role in the global climate system. It is through exchanges of radiative and turbulent heat fluxes, which are dependent on SSTs, that the ocean communicates its large thermal inertia to the atmosphere. Low-frequency variability in SSTs may provide a source of predictability for climate variability on interannual and longer time scales. As

* The National Center for Atmospheric Research is sponsored by the National Science Foundation.

Corresponding author address: Laura Ciasto, Climate Change Research Centre, University of New South Wales, Sydney NSW 2052, Australia.

E-mail: 1.ciasto@unsw.edu.au such, understanding the mechanisms that govern SST variability is central to an understanding of climate variability. The focus of the present study is to examine the temporal variability - and in particular the persistenceof large-scale extratropical SST anomalies.

In the limit of small lateral mixing, the upper-ocean mixed layer heat storage rate-or equivalently the tendency in SST_can be expressed as

$$
\begin{aligned}
\frac{\partial T}{\partial t}= & \frac{Q_{\mathrm{TH}}+Q_{\mathrm{RH}}}{\rho c_{p} H}+\left(\mathbf{U}_{g}+\mathbf{U}_{\mathrm{EK}}\right) \cdot \nabla T \\
& +\frac{\left(W_{e}+W_{\mathrm{EK}}\right)\left(T-T_{b}\right)}{H},
\end{aligned}
$$

where $T$ is the mixed layer temperature (equal to SST); $\rho$ is the density of seawater; $c_{p}$ is the heat capacity of 
seawater; $H$ is the depth of the mixed layer; $Q_{\mathrm{TH}}$ corresponds to the turbulent heat (sensible + latent) fluxes; $Q_{\mathrm{RH}}$ corresponds to the radiative (longwave + shortwave) heat fluxes; $\mathbf{U}_{g}$ and $\mathbf{U}_{\mathrm{EK}}$ are the geostrophic and Ekman velocities, respectively; $W_{e}$ is the vertical entrainment rate; $W_{\mathrm{EK}}$ is the Ekman pumping velocity; and $T_{b}$ is the temperature at depth that is entrained into the surface mixed layer.

The heat budget in Eq. (1) suggests that processes in both the atmosphere and ocean can influence the temporal variability and persistence of SST anomalies. In the atmosphere, the degree of temporal autocorrelation in the turbulent and radiative energy flux anomalies has been shown to impact the persistence of extratropical SST anomalies. For example, there is evidence to suggest that the turbulent heat fluxes associated with the remote extratropical atmospheric response to El NiñoSouthern Oscillation (ENSO) significantly impacts the persistence of the underlying SST anomalies in the North Pacific (Park et al. 2006) and South Pacific (Ciasto and Thompson 2008). Positive radiative-SST feedbacks in which interactions between SSTs and marine stratiform clouds impact the fraction of incoming solar radiation also influence the persistence of North Pacific SST anomalies during the warm season (Zhang et al. 1998; Norris et al. 1998; Park et al. 2006).

In the ocean, the depth of the mixed layer, vertical mixing, and horizontal heat transport can further influence the decorrelation time scales of SST anomalies. The depth of the mixed layer governs both the thermal inertia of the ocean mixed layer and the entrainment rate from below the mixed layer (Alexander et al. 2000). The latter can have a significant impact on the winterto-winter persistence of extratropical SST anomalies: SST anomalies created in the winter are sequestered beneath the relatively shallow mixed layer during the summer and then reentrained into the mixed layer in the following winter (Namias and Born 1970, 1974; Alexander and Deser 1995; Timlin et al. 2002; Ciasto and Thompson 2009). This "reemergence" mechanism can increase the memory of wintertime SST anomalies by more than a year (Deser et al. 2003) and when mean advection by ocean currents is taken into account, the winter-to-winter persistence of extratropical SST anomalies is further increased by 3-7 months (de Coëtlogon and Frankignoul 2003). On shorter time scales, entrainment has been shown to damp SST anomalies, which could potentially decrease the persistence of SST anomalies (Frankignoul 1985).

While all components of the upper-ocean heat budget can potentially influence the persistence of SST anomalies, the nature of extratropical SST variability can be simplified using the stochastic climate paradigm put forth by Frankignoul and Hasselmann (1977, hereafter FH77). Within this paradigm, the tendencies in SST are driven by random atmospheric forcing via surface turbulent heat fluxes and by heat advection due to Ekman currents. The SST anomalies are then damped via surface turbulent heat fluxes. Because the thermal inertia of the ocean mixed layer is relatively large, the resulting tendency in SST is only sensitive to the low-frequency component of the atmospheric forcing, and thus it exhibits a spectrum consistent with red noise. As a result, the atmospheric forcing, which has a decorrelation time scale of a few days to weeks, gives rise to SST anomalies with $e$-folding time scales of $\sim 3-6$ months. The paradigm presented by FH77 is consistent with the literature examining the initial decay of year-round extratropical SST anomalies (e.g., Namias et al. 1988; Lau and Nath 1996; Watanabe and Kimoto 2000; Deser et al. 2003; de Coëtlogon and Frankignoul 2003).

In the present study, the persistence of extratropical SST anomalies is examined within the framework proposed by FH77. Focus is placed on the patterns of largescale SST anomalies associated with the northern and southern annular modes (NAM and SAM, respectively), the leading patterns of extratropical atmospheric variability in each hemisphere. These nearly zonally symmetric modes of atmospheric variability are characterized by north-south vacillations in the midlatitude jet, such that a poleward contraction of the midlatitude jet (i.e., the high index polarity of the annular modes) is associated with anomalous westerlies along $50^{\circ}$ latitude and low pressure over the polar regions (Thompson and Wallace 2000). In the Northern Hemisphere, the NAM is nearly indistinguishable from the leading pattern of atmospheric variability in the North Atlantic sector, referred to as the North Atlantic Oscillation (NAO). The influence of the NAM in the North Pacific sector is weaker than in the Atlantic partly because of competing modes of variability, such as the Pacific-North America (PNA) pattern and the North Pacific Oscillation (NPO), and partly because of atmospheric teleconnections from the tropical Pacific (Deser 2000; Ambaum et al. 2001; Wallace and Thompson 2002).

Consequently, previous research on the direct impact of the NAM on the extratropical SST field (Fig. 1, left) has generally focused on the North Atlantic, where numerous studies have demonstrated that the meridionally banded "tripole" structure of SST anomalies associated with the NAM-NAO arises primarily from anomalous surface turbulent heat fluxes (Cayan 1992a,b) and horizontal heat advection by Ekman currents (Ekman heat fluxes; Luksch 1996; Seager et al. 2000; Visbeck et al. 2003; Deser et al. 2010). Similarly, in the Southern Ocean, the extratropical SST field associated with the SAM 

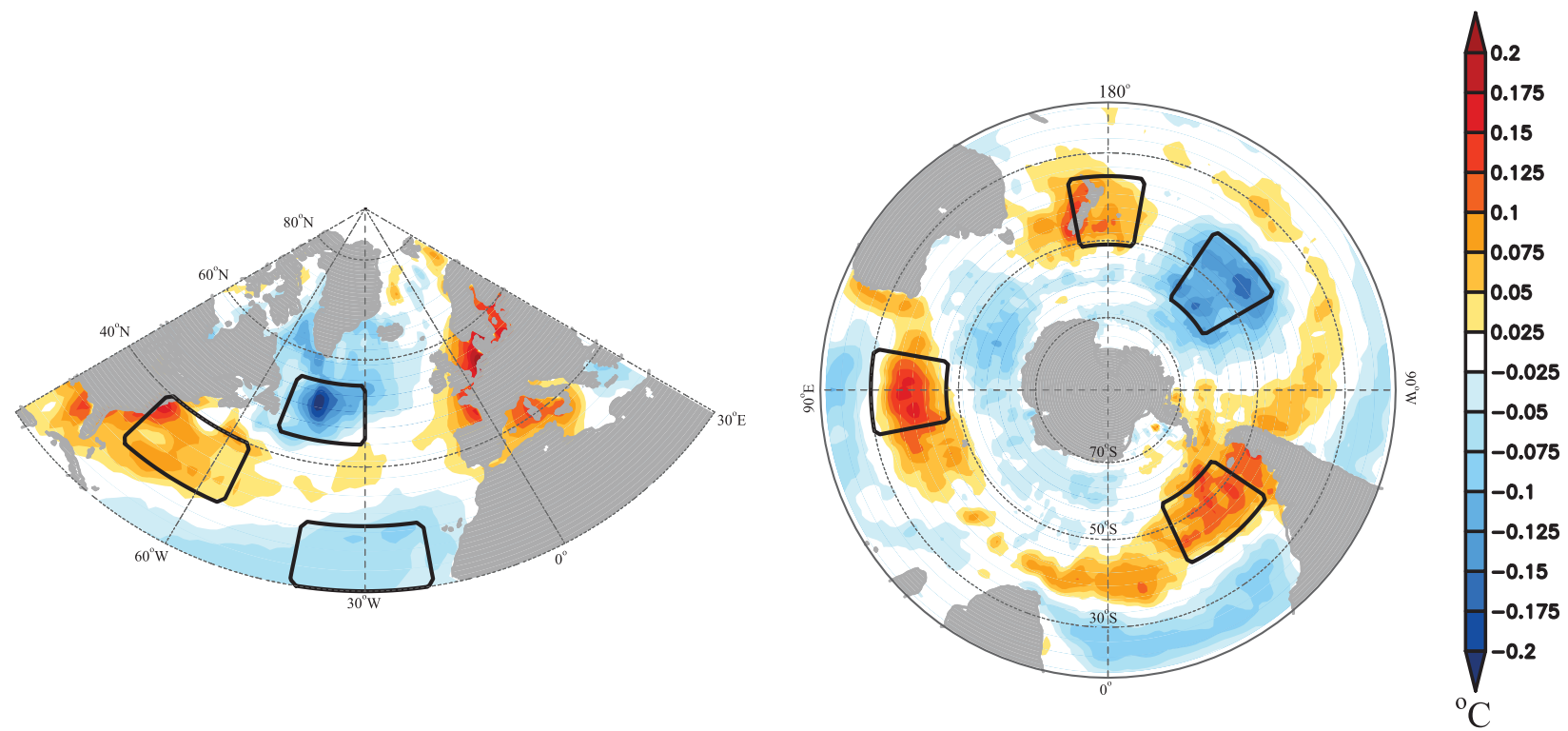

FIG. 1. Regressions of weekly-mean SST anomalies $\left({ }^{\circ} \mathrm{C}\right)$ onto standardized values of the (left) NAM and (right) SAM. Individual black boxes denote the regions analyzed in section 3 .

(Fig. 1, right) is primarily driven by surface turbulent heat fluxes with a smaller but nonnegligible contribution from horizontal Ekman heat fluxes (Sen Gupta and England 2006; Verdy et al. 2006; Ciasto and Thompson 2008).

The spatial variability of the SST anomalies associated with the annular modes is well documented in the literature, but the temporal persistence of extratropical SST anomalies associated with the NAM and SAM has received only cursory attention. While the tripole pattern of North Atlantic SST anomalies associated with the NAO-NAM has been shown to exhibit winter-towinter persistence via reemergence (de Coëtlogon and Frankignoul 2003; Cassou et al. 2007), there has been little research diagnosing the mechanisms of persistence of the NAM-related SST anomalies within the boreal cold season itself. In the Southern Ocean, Ciasto and Thompson (2008) briefly examined the relationship between seasonal variations in the depth of the mixed layer and the persistence of SAM-related SST anomalies; however, other mechanisms that could potentially impact the decorrelation time scales were not considered. Here, the goal of the present study is to provide one of the first comparisons between North Atlantic and Southern Ocean SST anomalies by using the FH77 paradigm to examine how the thermal inertia of the ocean mixed layer, as well as the atmospheric forcing and damping, impact the persistence of extratropical SST anomalies associated with the annular modes.

The rest of the paper is outlined as follows: Section 2 documents the data and methods used in this study. In section 3, the observed persistence of SST associated with the annular modes is examined along with the underlying physical mechanisms operating within the framework of the simple FH77 climate model. Section 4 examines the extent to which the time scales of the atmospheric forcing impact the time scales of the associated SST anomalies. Section 5 provides a summary of the key results.

\section{Data and methods}

Weekly-mean sea surface temperature data were obtained from the National Oceanic and Atmospheric Administration (NOAA) optimum interpolation (OI) dataset (Reynolds et al. 2002). The SST data are provided by the Office of Oceanic and Atmospheric Research (OAR) of NOAA's Earth System Research Laboratory (ERSL), Boulder, Colorado (www.esrl.noaa.gov/psd/). The OI SST data were derived from a blended objective analysis of in situ and satellite observations and are available on a $1^{\circ} \times 1^{\circ}$ latitude-longitude grid from 1981 to 2008.

Mixed layer depth data are from the Ocean Mixed Layer Depth Climatology Dataset as described in de Boyer Montégut et al. (2004). Data are available in monthly format on a $2^{\circ} \times 2^{\circ}$ latitude-longitude mesh and were derived from more than five million individual vertical profiles measured between 1941 and 2008, including data from Argo profilers, as archived by the National Oceanographic Data Center (NODC) and the World Ocean Circulation Experiment (WOCE). The depth of 
the mixed layer is defined as the uppermost depth at which temperature differs from the temperature at $10 \mathrm{~m}$ by $0.2^{\circ} \mathrm{C}$.

The geopotential height and surface turbulent (latent + sensible) heat flux data are from the National Centers for Environmental Prediction-National Center for Atmospheric Research (NCEP-NCAR) reanalysis (Kalnay et al. 1996), available from the NOAA/OAR/ESRL's Physical Sciences Division (PSD). The NCEP-NCAR reanalysis data are gridded on a $2.5^{\circ} \times 2.5^{\circ}$ latitudelongitude mesh. Heat advection by Ekman currents was calculated using wind stress measurements derived from the NCEP-NCAR reanalysis. It should be noted that there are known biases in the NCEP-NCAR reanalysis turbulent heat flux data (Josey 2001; Smith et al. 2001; Yu et al. 2004); other climatologies, such as the National Oceanography Centre, Southampton (NOC; Josey et al. 1998) and the Comprehensive Ocean-Atmosphere Data Set (COADS; da Silva et al. 1994), are more often used in the North Atlantic. However, the NOC and COADS data are both derived from in situ observations of which there are relatively few in the Southern Ocean, particularly poleward of $50^{\circ} \mathrm{S}$. Hence, the NCEP-NCAR reanalysis turbulent heat fluxes, which are part of a global reanalysis employing a data assimilation system, have improved spatial coverage. Furthermore, the reanalysis heat fluxes have been shown to correspond well with the observed SST anomalies associated with large-scale atmospheric circulation variability in the North Atlantic (e.g., Deser and Timlin 1997) and Southern Oceans (Sen Gupta and England 2006; Screen et al. 2010).

The SAM and NAM indices were obtained from NOAA's Climate Prediction Center (CPC). Daily mean values of the SAM (NAM) are found by projecting daily $700-\mathrm{mb}(1000 \mathrm{mb})$ height anomalies poleward of $20^{\circ}$ onto the leading empirical orthogonal function of monthlymean 700-mb (1000 mb) heights, calculated for the period 1979-2000. The high index polarity of the NAM and SAM are characterized by negative height anomalies over the pole surrounded by positive height anomalies at $\sim 45^{\circ}-55^{\circ}$. Both indices were standardized by subtracting the long-term mean and dividing by the long-term standard deviation. Note that the indices of the NAM, which corresponds to the leading pattern of Northern Hemisphere atmospheric variability, and the NAO, which corresponds to the leading pattern of North Atlantic atmospheric variability, are highly correlated at 0.89 (Hurrell et al. 2003). Furthermore, in this study, the analyses based on the NAM index were repeated using the NAO index and the results of these analyses were not sensitive to the choice of index.

In this study, we make extensive use of autocorrelation analyses to examine the persistence of extratropical
SST anomalies associated with the annular modes. Statistical significance of the correlation coefficients is assessed using a one-tailed Student's $t$ test based on an effective sample size determined from the method outlined in Bretherton et al. (1999). The results presented here are divided into the warm season, corresponding to November-April in the Southern Ocean and MayOctober in the North Atlantic, and the cold season, corresponding to May-October in the Southern Ocean and November-April in the North Atlantic. Before calculating the autocorrelations, the data were first detrended to avoid "reddening" related to long-term trends. Furthermore, the Niño-3.4 index (i.e., SST anomalies averaged over the region $5^{\circ} \mathrm{S}-5^{\circ} \mathrm{N}, 170^{\circ}-120^{\circ} \mathrm{W}$ ) was linearly regressed from the data to avoid persistence in SST anomalies associated with the low-frequency variability inherent in ENSO. While linear regression of the Niño3.4 index from the data removes a large fraction of the SST persistence related to ENSO variability (Ciasto and Thompson 2008), there is likely to be some residual influence of ENSO. However, ENSO is only significantly correlated to SAM variability and only during the austral warm season (L'Heureux and Thompson 2006). Accordingly, linearly removing the ENSO signal from Southern Ocean cold-season data and from North Atlantic warm- and cold-season data had little impact on the results.

\section{Autocorrelations of observed and simulated SST anomalies associated with the annular modes}

The top panel of Fig. 2 shows the autocorrelation functions of the observed year-round expansion coefficient time series of the North Atlantic SST anomalies associated with the NAM (blue line; $\mathrm{SST}_{\mathrm{NAM}}$ ) and the Southern Ocean SST anomalies associated with the SAM (black line; SST $_{\text {SAM }}$ ). The expansion coefficient time series were formed by projecting weekly-mean North Atlantic (Southern Ocean) SST anomalies onto maps of North Atlantic (Southern Ocean) SST anomalies regressed onto standardized values of the NAM (SAM) shown in Fig. 1.

When all seasons are considered, the autocorrelations of $\mathrm{SST}_{\mathrm{SAM}}$ remain statistically significant within the first three months; however, the autocorrelations of $\mathrm{SST}_{\mathrm{NAM}}$ exhibit less persistence, decaying to $\sim 0.2$ over the same period. A subdivision of the data into warm and cold seasons (Fig. 2, bottom panel) reveals that during the warm season, there exist negligible differences between the autocorrelation functions of the $\mathrm{SST}_{\mathrm{SAM}}$ and $\mathrm{SST}_{\mathrm{NAM}}$, both decaying to $\sim 0.3$ after 3 months. During the cold season, the autocorrelation curve of $\mathrm{SST}_{\mathrm{NAM}}$ continues to exhibit a rapid decay; however, the autocorrelation curve 

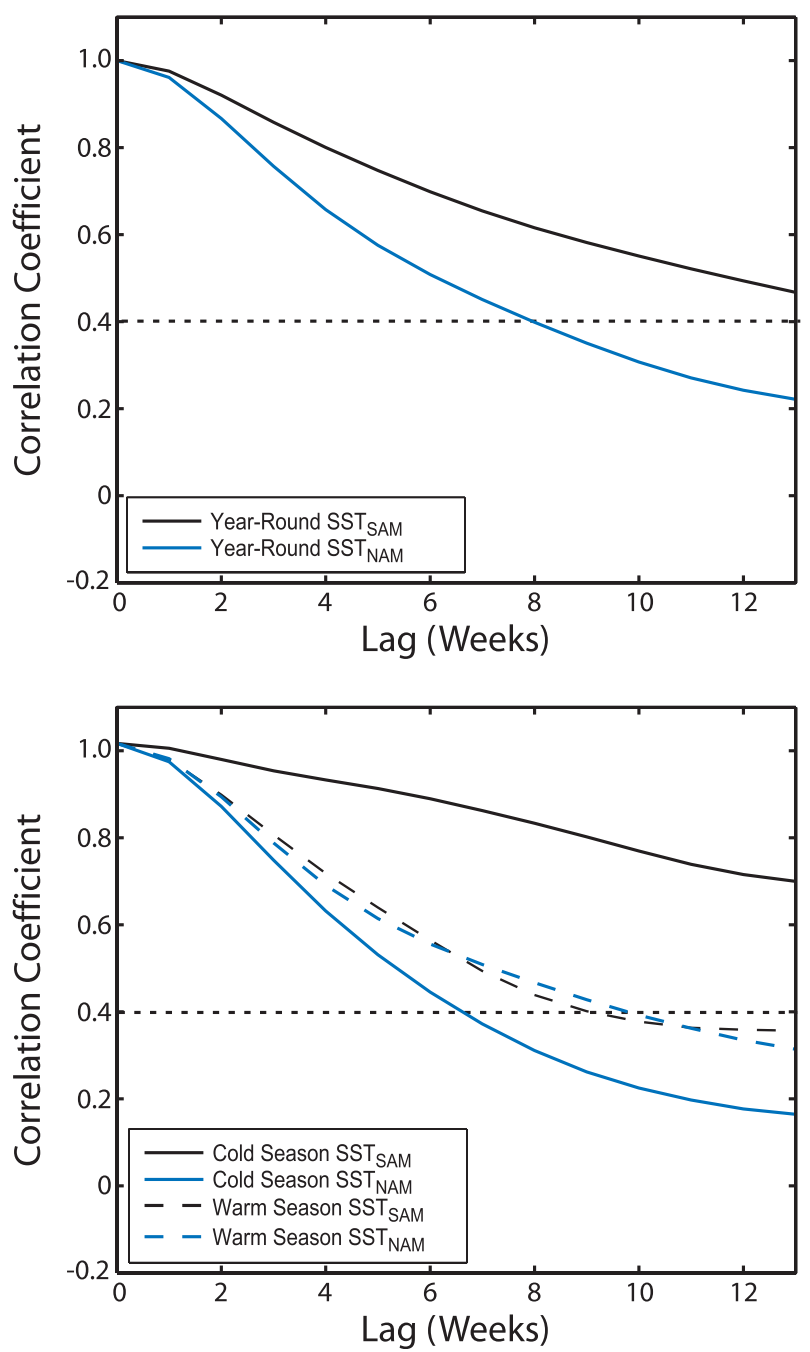

FIG. 2. Autocorrelation functions of the expansion coefficient time series of the observed (top) year-round and (bottom) hemispheric warm-season (dashed) and cold-season (solid) SST pattern associated with the SAM (black) and NAM (blue). Correlations exceeding 0.4 are statistically significant at the $95 \%$ confidence level (short-dashed black line).

of $\mathrm{SST}_{\mathrm{SAM}}$ features a considerably higher degree of persistence, characterized by correlations of $\sim 0.7$ after 3 months. The results in Fig. 2 are not sensitive to small changes ( \pm 4 weeks) in the definition of the warm and cold seasons. Furthermore, similar results were obtained when the analysis was repeated separately on the first and second halves of each season.

In the following analysis, the simple stochastic climate paradigm described in FH77 is used to explore how atmospheric forcing and damping of SST anomalies, as well as its influence on ocean mixed layer depth, control the persistence of extratropical SST anomalies associated with the NAM and the SAM. The analysis focuses primarily on the cold season, when the interhemispheric differences in SST persistence are largest. The governing equation for the FH77 model is

$$
\rho c_{p} H \frac{d T^{\prime}}{d t}=F^{\prime}-\lambda T^{\prime},
$$

where $\rho$ is the density of seawater $\left(1000 \mathrm{~kg} \mathrm{~m}^{-3}\right) ; c_{p}$ is the heat capacity of seawater $\left(4218 \mathrm{~J} \mathrm{~kg}^{-1} \mathrm{~K}^{-1}\right) ; H$ is the depth of the ocean mixed layer; $T^{\prime}$ is the temperature anomaly; $F^{\prime}$ represents the atmospheric forcing; and $\lambda$ corresponds to the linearized damping parameter, which represents the damping of $T^{\prime}$ back to atmospheric temperature via turbulent heat fluxes.

The ocean mixed layer depths are taken to be 65 and $100 \mathrm{~m}$ in the North Atlantic $\left(H_{\mathrm{NA}}\right)$ and Southern Ocean $\left(H_{\mathrm{SO}}\right)$ basins, respectively. The mixed layer depths are determined by computing the individual regression coefficients of the cold-season SST anomalies onto the annular mode (i.e., regressing North Atlantic SST anomalies onto the NAM and Southern Ocean SST anomalies onto the SAM), weighted by the climatological mean coldseason mixed layer depth at each gridpoint in the North Atlantic $\left(20^{\circ}-80^{\circ} \mathrm{N}, 90^{\circ} \mathrm{W}-30^{\circ} \mathrm{E}\right)$ and Southern Ocean $\left(20^{\circ}-80^{\circ} \mathrm{S}, 0^{\circ}-360^{\circ} \mathrm{E}\right)$ basins.

The damping coefficient $\lambda$ is given as $25 \mathrm{Wm}^{-2} \mathrm{~K}^{-1}$ in both the North Atlantic and Southern Ocean basins and was chosen based on previous studies that have demonstrated values of $\lambda$ ranging from 15 to $35 \mathrm{Wm}^{-2} \mathrm{~K}^{-1}$ during the Northern Hemisphere cold season (Barsugli and Battisti 1998; Frankignoul et al. 1998; Deser et al. 2003; Park et al. 2005). A relative lack of in situ observations has limited calculations of $\lambda$ in the extratropical Southern Hemisphere; however, Park et al. (2005) estimate the values in the range $15-35 \mathrm{Wm}^{-2} \mathrm{~K}^{-1}$ equatorward of $40^{\circ} \mathrm{S}$, consistent with those calculated in the North Atlantic.

The model in Eq. (2) is first used to determine whether the differences in the depth of the ocean mixed layer, which is somewhat shallower in the North Atlantic than in the Southern Ocean, can explain the observed differences in the persistence of cold-season $\mathrm{SST}_{\mathrm{SAM}}$ and $\mathrm{SST}_{\mathrm{NAM}}$. To isolate the influence of the mixed layer depth, the forcing $F^{\prime}$ is specified as a white-noise time series. Because white noise is, by definition, uncorrelated with itself at all lags except zero, the autocorrelation function ( $r$ ) of $T^{\prime}$ of Eq. (2) can be written as a function of lag $(\tau)$ as follows:

$$
r(\tau)=e^{-\lambda \tau / \rho c_{p} H} .
$$

Equation (3) demonstrates that the autocorrelation function of $T^{\prime}$ is exponentially dependent on $H$ (i.e., the thermal inertia of the ocean mixed layer) and $\lambda$, the rate 


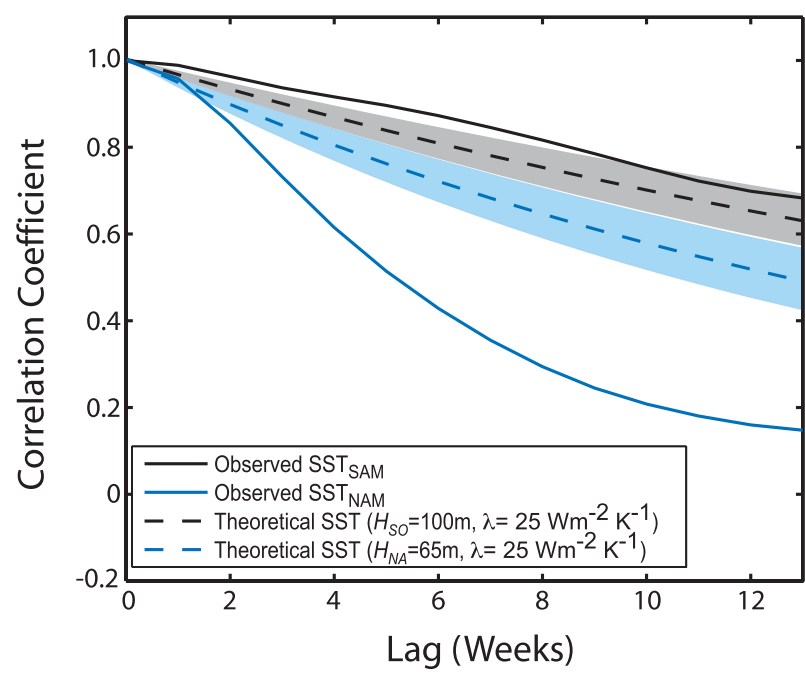

FIG. 3. Autocorrelation functions of the expansion coefficient time series of the observed cold-season SST pattern associated with the SAM (solid black) and NAM (solid blue). The dashed lines correspond to the solutions to Eq. (3) for $\rho=1000 \mathrm{~kg} \mathrm{~m}^{-3}, c_{p}=$ $4218 \mathrm{~J} \mathrm{~kg}^{-1} \mathrm{~K}^{-1}, \lambda=25 \mathrm{~W} \mathrm{~m}^{-2} \mathrm{~K}^{-1}$, and mixed layer depths of $H_{\mathrm{SO}}=100 \mathrm{~m}$ (black dashed) and $H_{\mathrm{NA}}=65 \mathrm{~m}$ (blue dashed). The shading corresponds to the range of solutions to Eq. (3) for $\lambda=20$ $30 \mathrm{~W} \mathrm{~m}^{-2} \mathrm{~K}^{-1}$

at which $T^{\prime}$ is damped via turbulent heat fluxes. The formulation of the FH77 model represented by Eq. (3) is referred to as the "white noise" model.

In the first case, $\lambda$ is assumed to be $25 \mathrm{~W} \mathrm{~m}^{-2} \mathrm{~K}^{-1}$ in both the North Atlantic and Southern Oceans, and thus the autocorrelation functions of $T^{\prime}$ are only dependent on $H_{\mathrm{NA}}$ and $H_{\mathrm{SO}}$. Figure 3 shows the theoretical autocorrelation curves derived from Eq. (3) for $H_{\mathrm{NA}}$ (dashed blue) and $H_{\mathrm{SO}}$ (dashed black) as well as the observed cold-season SST $_{\text {NAM }}$ (solid blue) and SST $_{\text {SAM (solid }}$ black). Consistent with Ciasto and Thompson (2008), the theoretical decay of $T^{\prime}$ based on $H_{\mathrm{SO}}$ exhibits strong agreement with the $\mathrm{SST}_{\mathrm{SAM}}$. However, there is considerably less agreement between the theoretical and observed autocorrelation functions in the North Atlantic. While the mixed layer in the North Atlantic is shallower than the Southern Ocean, the theoretical autocorrelation function derived using $H_{\mathrm{NA}}$ decays only slightly faster than the function derived using $H_{\mathrm{SO}}$. As a result, the theoretical autocorrelation function based upon $H_{\mathrm{NA}}$ drastically overestimates the persistence of the cold-season SST $_{\text {NAM }}$.

The theoretical autocorrelation functions derived from the white-noise model are strongly dependent on our estimates of $H_{\mathrm{SO}}$ and $H_{\mathrm{NA}}$, which are simplified representations of the ocean mixed layer depths, as they are calculated over several months and across large regions spanning values from less than 50 to more than $400 \mathrm{~m}$ (not shown). However, in the Southern Ocean, the theoretical autocorrelation functions derived from $H_{\mathrm{SO}}$ are not highly sensitive to reasonable changes in mixed layer depths (i.e., similar theoretical autocorrelation functions are obtained for $H_{\text {SO }}$ ranging from 75 to $150 \mathrm{~m}$ ). In the North Atlantic, decreasing $H_{\mathrm{NA}}$ to values less than $65 \mathrm{~m}$ would decrease the persistence of the resulting $T^{\prime}$; however, to produce a theoretical autocorrelation function that provides reasonable agreement with that of the observed $\mathrm{SST}_{\mathrm{NAM}}$, the assumed $H_{\mathrm{NA}}$ would have to be $\sim 25 \mathrm{~m}$, a depth that is considerably shallower than observations across much of the North Atlantic basin during the boreal cold season.

The impact of $\lambda$ on the persistence of SST anomalies is assessed by solving Eq. (3) for a range of $\lambda=20$ $30 \mathrm{~W} \mathrm{~m}^{-2} \mathrm{~K}^{-1}$. According to Eq. (3), the autocorrelation function of $T^{\prime}$ is inversely proportional to $\lambda$ such that, assuming that $H$ is constant, increased damping to the atmosphere would decrease persistence of the ocean temperature anomalies. The results reveal that changing the damping coefficient only slightly modifies the theoretical autocorrelation function derived using $H_{\text {SO }}$ (Fig. 3 , light gray shading). The theoretical autocorrelations based on $H_{\mathrm{NA}}$ are also only marginally reduced as $\lambda$ increases and still drastically overestimates the persistence of the observed cold-season $\operatorname{SST}_{\mathrm{NAM}}$ (Fig. 3, light blue shading). To generate a theoretical autocorrelation function similar to the observations (assuming $H=$ $\left.H_{\mathrm{NA}}\right), \lambda$ would have to be $65-70 \mathrm{~W} \mathrm{~m}^{-2} \mathrm{~K}^{-1}$, a value that is well outside the observed range (Frankignoul et al. 1998; Park et al. 2005).

The analysis above assumes that the surface turbulent and Ekman heat fluxes associated with the annular modes have little-to-no memory and can be approximated as white noise. This assumption is evaluated now by solving Eq. (2) for $T^{\prime}$ using the same values of $\lambda, H_{\mathrm{SO}}$, and $H_{\mathrm{NA}}$ as in the white-noise model; however, $F^{\prime}$ is now defined as the sum of the observed cold-season surface turbulent and Ekman heat fluxes associated with the NAM and the SAM. This formulation of the FH77 model in Eq. (2) is referred to as the "observed heat flux" model. Note that the surface radiative heat fluxes associated with the annular modes are not included in this heat flux formulation. Previous studies have noted the impact of radiative heat fluxes on the persistence of warm-season SST anomalies (Norris et al. 1998; Park et al. 2005). However, the results described below remain virtually unchanged when the radiative heat fluxes, which exhibit one-third of the amplitude of the surface turbulent heat fluxes, were considered. We thus hereafter analyze the observed heat flux model with the radiative heat flux terms ignored.

When Eq. (2) is forced with the observed surface turbulent and Ekman heat fluxes associated with the 


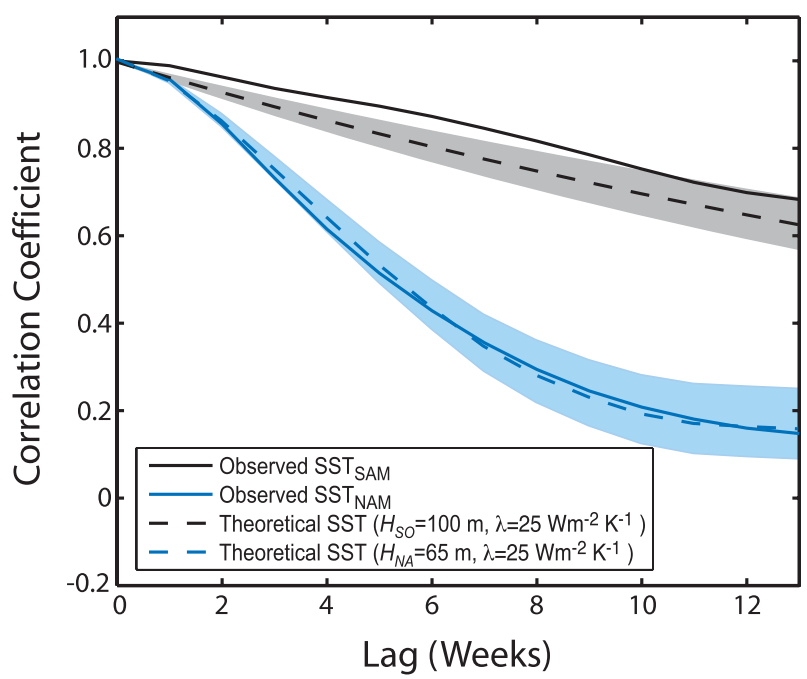

FIG. 4. Autocorrelation functions of the expansion coefficient time series of the observed cold-season SST pattern associated with the SAM (solid black) and NAM (solid blue). The dashed lines correspond to the autocorrelations of the solutions to Eq. (2) for $\rho=1000 \mathrm{~kg} \mathrm{~m}^{-3}, c_{p}=4218 \mathrm{~J} \mathrm{~kg}^{-1} \mathrm{~K}^{-1}$, and $\lambda=25 \mathrm{~W} \mathrm{~m}^{-2} \mathrm{~K}^{-1}$. Here $F$ is given as the observed surface turbulent + Ekman heat flux anomalies associated with the SAM and NAM, and mixed layer depths of $H_{\mathrm{SO}}=100 \mathrm{~m}$ (black dashed) and $H_{\mathrm{NA}}=65 \mathrm{~m}$ (blue dashed). The shading corresponds to the range of solutions to Eq. (2) for $\lambda=20-30 \mathrm{~W} \mathrm{~m}^{-2} \mathrm{~K}^{-1}$.

SAM, the resulting theoretical autocorrelations (Fig. 4; black dashed curve) yield approximately the same degree of persistence as the autocorrelation function derived from the white-noise model (i.e., compare the black dashed curves in Figs. 3 and 4) and thus the theoretical autocorrelations still exhibit good agreement with the cold-season $\mathrm{SST}_{\mathrm{SAM}}$. However, the theoretical $T^{\prime}$ derived using the observed NAM-related fluxes and $H_{\mathrm{NA}}$ (Fig. 4; blue dashed curve) now decays such that the associated autocorrelations decrease to $\sim 0.2$ within the first 3 months, which is considerably faster than the decay derived from the white-noise model (i.e., compare the blue dashed curves in Figs. 3 and 4), and now shows improved agreement with the observed decay of the coldseason $\mathrm{SST}_{\mathrm{NAM}}$. Similar to the results from the whitenoise model, the theoretical autocorrelation functions derived from the observed heat flux model are not strongly sensitive to the feedback parameter $\lambda$ in the range of $20-30 \mathrm{~W} \mathrm{~m}^{-2} \mathrm{~K}^{-1}$.

The robustness of the results in Figs. 3 and 4 is evaluated by examining the persistence of observed SST anomalies associated with the NAM and SAM across smaller spatial scales. In this analysis, the observed autocorrelations are not based on regressions onto the NAM or SAM but rather correspond to a time series averaged over a geographically limited region impacted by the NAM-SAM. For example, Fig. 5 shows the observed autocorrelation functions of area-averaged coldseason SST anomalies (blue solid line) over three regions impacted by the NAM: the subpolar North Atlantic $\left(45^{\circ}-55^{\circ} \mathrm{N}, 30^{\circ}-50^{\circ} \mathrm{W}\right.$; top panel), the Sargasso Sea $\left(30^{\circ}-40^{\circ} \mathrm{N}, 55^{\circ}-75^{\circ} \mathrm{W}\right.$; middle panel), and the subtropical North Atlantic $\left(20^{\circ}-30^{\circ} \mathrm{N}, 20^{\circ}-40^{\circ} \mathrm{W}\right.$; bottom panel). Also plotted in Fig. 5 are the theoretical autocorrelation functions derived from Eq. (3) (white-noise model; dashed red line) and derived from Eq. (2) with $F^{\prime}$ specified as the area-averaged observed total heat flux anomalies (i.e., the observed heat flux model; blue dashed line).

The results in Fig. 5 reveal that the temporal behavior of regional-scale area-averaged cold-season North Atlantic SST anomalies is broadly consistent with that of the basinwide SST projections onto the NAM. Similar to $\mathrm{SST}_{\mathrm{NAM}}$, the observed area-averaged SST anomalies in the three regions of the North Atlantic experience rapid decay to $\sim(0.2-0.3)$ within the first three months. Because the average cold-season mixed layer depths in these regions are similar to, or larger than, $H_{\mathrm{NA}}$ used in the basinwide $\mathrm{SST}_{\mathrm{NAM}}$ analysis, the theoretical autocorrelation functions of $T^{\prime}$ derived from the white-noise model, which is dependent on $H$, largely overestimate the persistence of the SST anomalies in all three regions. The theoretical autocorrelation functions derived from the observed heat flux model, which is dependent on the observed area-averaged surface turbulent and Ekman heat fluxes as well as $H$, provide a better estimation of the observed SST autocorrelations, particularly in the subpolar North Atlantic.

In the Southern Ocean, four regions impacted by the SAM were chosen: the central Pacific $\left(40^{\circ}-60^{\circ} \mathrm{S}, 120^{\circ}-\right.$ $\left.140^{\circ} \mathrm{W}\right)$, the western Pacific $\left(35^{\circ}-50^{\circ} \mathrm{S}, 170^{\circ} \mathrm{E}-170^{\circ} \mathrm{W}\right)$, the central Indian Ocean $\left(30^{\circ}-45^{\circ} \mathrm{S}, 80^{\circ}-100^{\circ} \mathrm{E}\right)$, and the South Atlantic $\left(40^{\circ}-55^{\circ} \mathrm{S}, 25^{\circ}-55^{\circ} \mathrm{W}\right)$. The area-averaged cold-season SST anomalies in the two Pacific sectors exhibit relatively long decorrelation time scales (Fig. 6), similar to the basinwide Southern Ocean SAM-related SST anomalies. There is also strong agreement between the theoretical $T^{\prime}$ derived from the white-noise model and that derived from the observed heat flux model. In the South Atlantic, the area-averaged SST anomalies, which are less persistent than the cold-season SST $_{\mathrm{SAM}}$, exhibit reasonable agreement with the results obtained from the observed heat flux model; however, the observed autocorrelation function is somewhat overestimated by the white-noise model. A notably different situation is observed in the Indian Ocean, where the area-averaged SST anomalies are largely overestimated by the theoretical autocorrelations of $T^{\prime}$ derived from either the white noise or the observed heat flux models. 

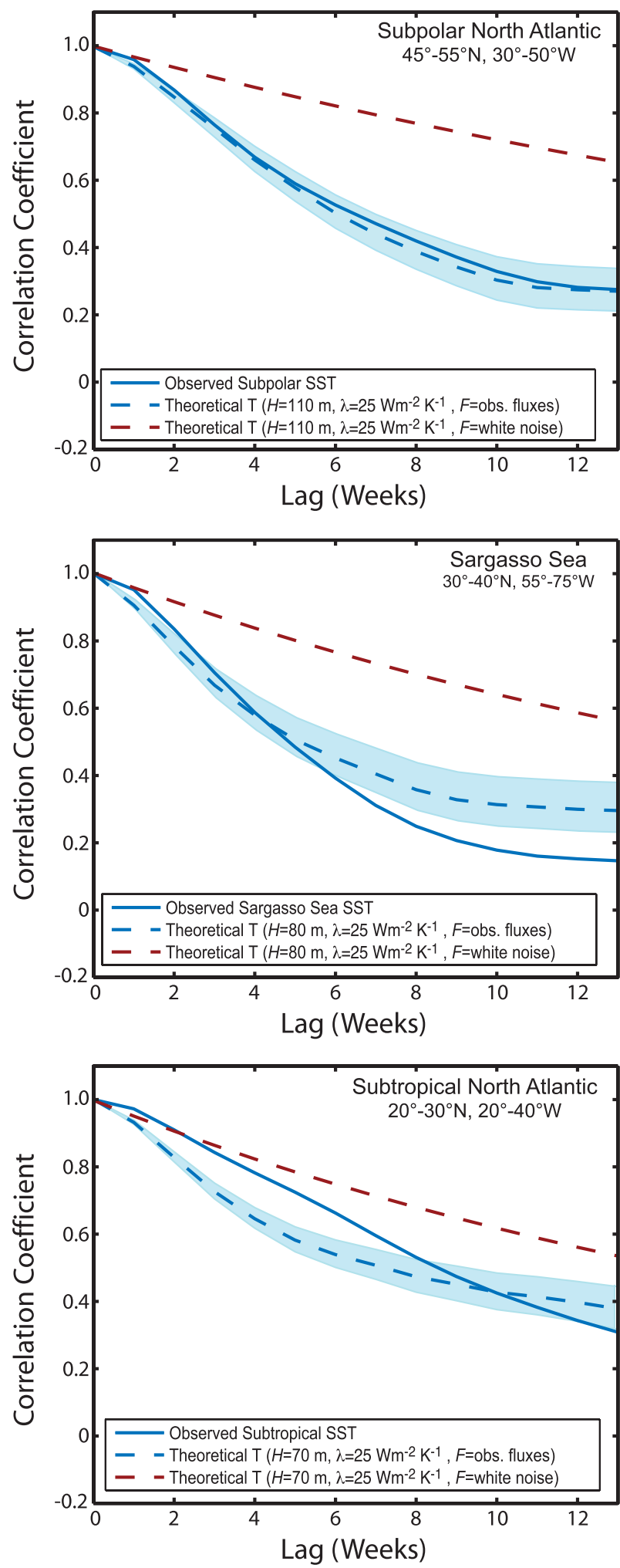

FIG. 5. Autocorrelations of observed area-averaged cold-season SST anomalies (solid blue), $T^{\prime}$ derived from the observed heat flux model in Eq. (2) (dashed blue line), and $T^{\prime}$ derived from the whitenoise model in Eq. (3) (dashed red line) for the (top) subpolar
One possible explanation for this is that the depth of the mixed layer has been overestimated in the Indian Ocean, a region that has limited in situ observations available to calculate the mixed layer depth. However, it is also possible that the simple formulation of Eq. (2) is not sufficient to capture the persistence of SST variability in the Indian Ocean, and that neglected mechanisms, such as mean advection by ocean currents, eddies, and/or ocean mixed layer processes, play a more dominant role.

\section{Lagged analysis of the atmospheric circulation associated with the annular modes}

The results from the previous section suggest that the persistence of Southern Ocean SST anomalies associated with the SAM can be largely determined by the thermal inertia of the ocean mixed layer, whereas the persistence of the North Atlantic SST anomalies associated with the NAM appear to be further impacted by deviations of the observed surface turbulent and Ekman heat fluxes from white noise. In this section, we further examine the atmospheric forcing associated with the annular modes and the extent to which it affects the persistence of the resulting SST anomalies. Figure 7 shows the autocorrelation functions of the surface turbulent heat fluxes associated with the SAM and NAM (top panel) as well as the NAM- and SAM-related Ekman heat fluxes (middle panel) and the total (i.e., turbulent + Ekman) heat fluxes (bottom panel). For both the NAM and SAM, the autocorrelation functions of the turbulent heat fluxes are similar to those of the Ekman heat fluxes. However, the amplitude of the surface turbulent heat fluxes are approximately twice that of the Ekman heat fluxes (not shown), and thus the detailed structure of the autocorrelation functions of the total heat fluxes primarily reflects the persistence of the surface turbulent heat fluxes.

The bottom panels of Fig. 7 reveal that the autocorrelation functions of the total heat fluxes associated with the SAM and NAM are similar over the first few weeks, exhibiting $e$-folding time scales of $1-2$ weeks (i.e., the time in which the autocorrelations decrease to 1/e); however, between weeks 2 and 9, the NAM-related heat flux autocorrelations are consistently lower than those associated with the SAM. During that time, the SAMrelated heat fluxes remain significantly correlated at

North Atlantic, (middle) Sargasso Sea, and (bottom) subtropical North Atlantic. The blue shading corresponds to the range of solutions to Eq. (2) for $\lambda=20-30 \mathrm{~W} \mathrm{~m}^{-2} \mathrm{~K}^{-1}$ for each region. 

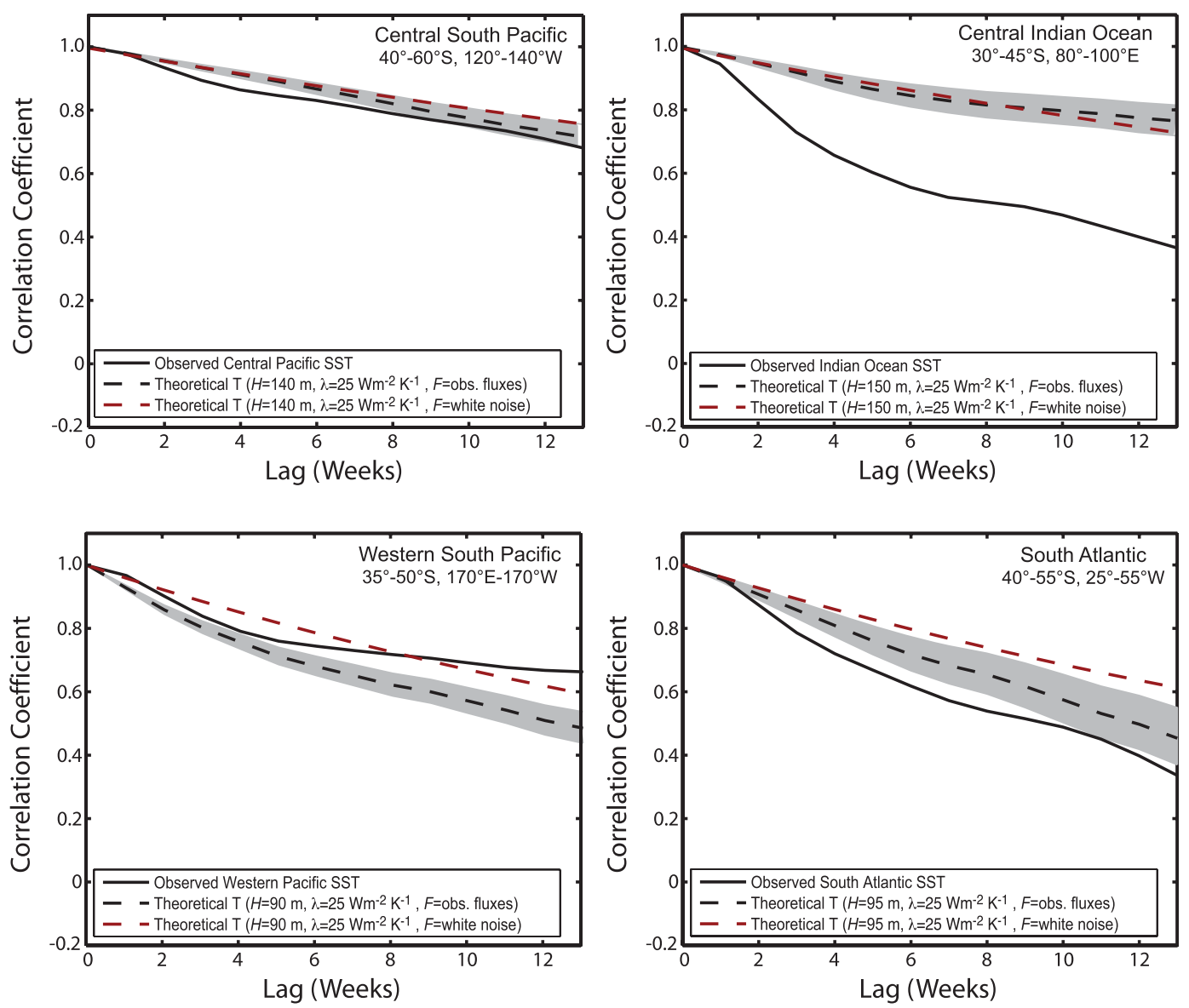

FIG. 6. As in Fig. 5, but for the (top left) central South Pacific, (bottom left) western South Pacific, (top right) central Indian Ocean, and (bottom right) South Atlantic. The gray shading corresponds to the range of solutions to Eq. (2) for $\lambda=20-30 \mathrm{~W} \mathrm{~m}^{-2} \mathrm{~K}^{-1}$ for each region.

the $95 \%$ confidence level $(r>0.1)$, whereas the NAMrelated heat fluxes become weakly but significantly negatively correlated at $\sim 7$ weeks, indicating that the NAM-related heat fluxes change sign after 1-2 months. It should be noted that the autocorrelation functions of the SAM and NAM (or NAO) indices (not shown) do not show noticeable differences: both exhibit $e$-folding time scales of 1-2 weeks and remain positively correlated $(r \sim 0.1)$ for the first $\sim 2$ months but neither exhibits negative correlations.

The out-of-phase behavior of the NAM-related heat fluxes seen in Fig. 7 is modest; however, Fig. 8 illustrates similar behavior that is also evident in the regressions of North Atlantic surface turbulent and Ekman heat fluxes (shading), and 1000 -hPa height $\left(Z_{1000}\right.$, contours) anomalies onto the NAM at lags ranging from 0 to 8 weeks (i.e., heat fluxes $-Z_{1000}$ lag the NAM). During the first few weeks, the total heat flux anomalies associated with the positive phase of the NAM decay as the overlying atmospheric circulation weakens. However, after approximately four weeks, the heat fluxes equatorward of $45^{\circ} \mathrm{N}$ in the North Atlantic reversed sign and now resemble a pattern associated with the negative phase of the NAM. Qualitatively similar results are obtained when the regression analysis was repeated using the NAO index.

The evolution of the heat fluxes appear to be partially consistent with changes in the structure of the atmospheric circulation, which still projects onto the NAMNAO, but the height anomalies in the eastern Atlantic have now contracted and shifted poleward and eastward. Consequently, southerly winds are now observed over $45^{\circ}-55^{\circ} \mathrm{N}$, producing warm-air advection and generating positive heat fluxes in that region. It is also possible that the sign reversal of the total heat flux anomalies represents a local response through which the atmospheric temperatures adjust to the underlying SST anomalies (Barsugli and Battisti 1998). However, whether the cyclonic circulation anomaly at $25^{\circ} \mathrm{N}$ represents a dynamical response of the atmosphere to the NAM-induced SST 

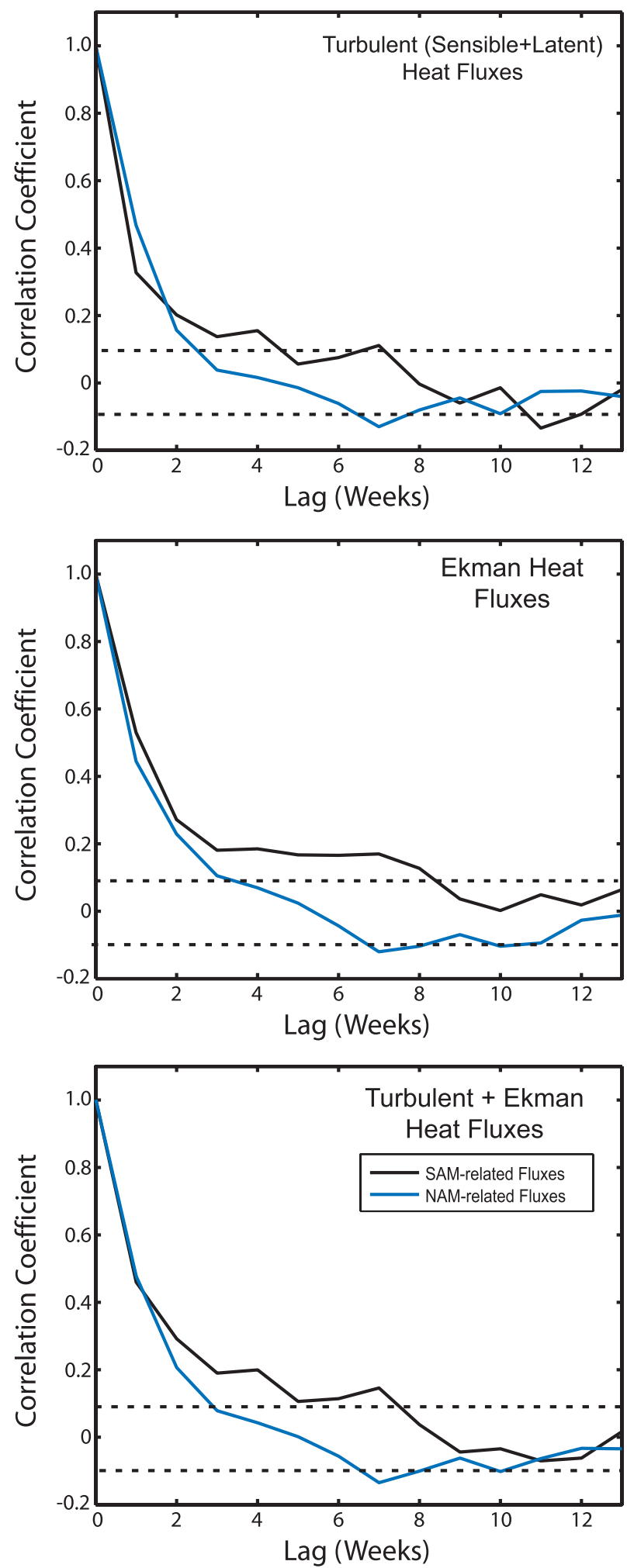

FIG. 7. Autocorrelation functions of the expansion coefficient time series of the cold-season (top) surface turbulent, (middle) Ekman heat, and (bottom) turbulent + Ekman heat flux patterns associated with the cold-season SAM (black) and NAM (blue). Correlations exceeding \pm 0.1 are statistically significant at the $95 \%$ confidence level (short-dashed lines). anomaly pattern or is an inherent feature of the decay of the NAM remains to be determined.

In the Southern Ocean, the nearly zonally symmetric structure of the atmospheric circulation associated with the positive phase of the SAM also weakens within the first several weeks (Fig. 9), but the centers of action over New Zealand and west of the Antarctic Peninsula retain a substantial fraction of their amplitude-structure for several weeks. It is not clear why the detrended height anomalies persist for several weeks; however, as a result of this atmospheric persistence, the underlying surface turbulent and Ekman heat fluxes are observed for several weeks and do not exhibit out-of-phase behavior at any lag.

The results in Figs. 7-9 suggest at least two possible scenarios through which the surface turbulent and Ekman heat fluxes related to the annular modes could impact the persistence of the associated SST anomalies.

1) The relatively high persistence of the SAM-related fluxes in turn increases the persistence of the resulting SAM-related SST anomalies.

Because the surface turbulent and Ekman heat fluxes associated with the SAM exhibit variability that persists significantly longer than white noise, it is possible that the resulting SST anomalies reflect this increased persistence in atmospheric forcing. This possibility is assessed using a first-order Markov model, namely,

$$
F(t)=\sum_{i=1}^{N} a F(t-i)+\left(1-a^{2}\right) \varepsilon(t),
$$

where $a$ corresponds to the lag- 1 autocorrelation that measures the memory at a previous time $t$ and $\varepsilon$ is the white-noise time series. According to Eq. (4), the $e$-folding time scale (i.e., the persistence) of the time series $F$ increases as the lag- 1 autocorrelation $a$ increases.

For a range of $e$-folding time scales from 1 to 13 weeks, the model in Eq. (4) is used to calculate $F$, which is then used in Eq. (2) to solve for $T^{\prime}$ using $H=100 \mathrm{~m}$ and $\lambda=25 \mathrm{~W} \mathrm{~m}^{-2} \mathrm{~K}^{-1}$. Figure 10 demonstrates that the $e$-folding time scale of $T^{\prime}$ increases monotonically as the $e$-folding time scale of $F$ also increases. However, the $e$-folding time scale of $T^{\prime}$ only increases by a few weeks when the $e$-folding time scale of the atmospheric forcing increases from 0 (i.e., white noise) to 1-2 weeks (the $e$-folding time scale of SAMrelated fluxes). These results suggest that although the SAM-related heat fluxes exhibit significantly more persistence than white noise, that increased persistence does not significantly impact the persistence of 


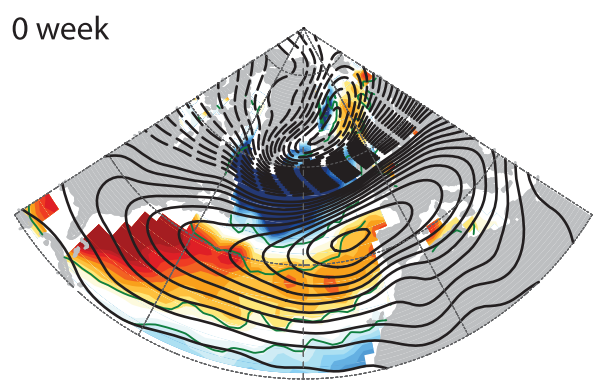

\section{2 weeks}

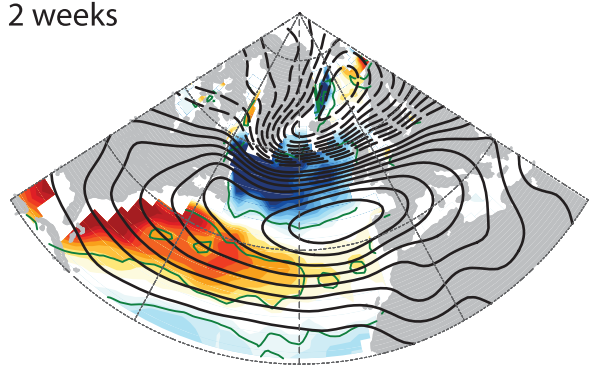

4 weeks

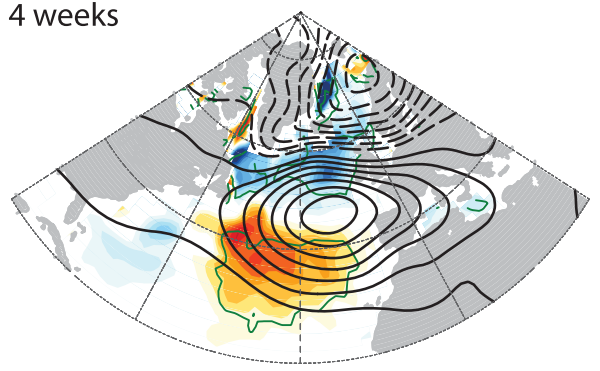

6 weeks
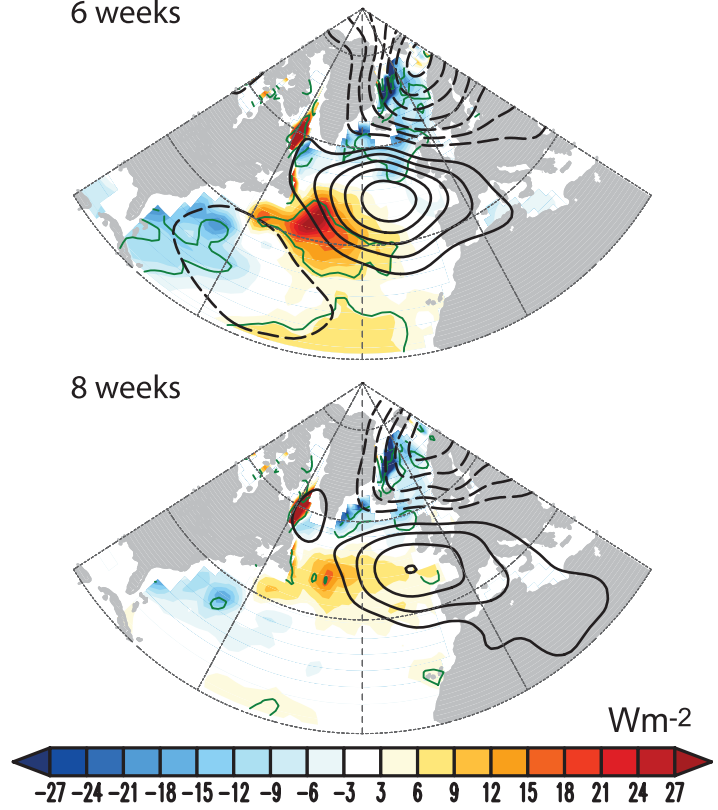

FIG. 8. Weekly-mean cold-season surface turbulent + Ekman flux (shading) and $Z_{1000}$ (contours) anomalies regressed onto weekly values of the NAM index at (top) 0 week, (second from top) 2 weeks, (middle) 4 weeks (NAM leads), (second from bottom) 6 weeks, and (bottom) 8 weeks. Positive heat fluxes are directed into the ocean and are given in $\mathrm{W} \mathrm{m}^{-2}$. Positive (negative) contours correspond to solid (dashed) lines of $Z_{1000}(\mathrm{~m})$ and are drawn at 3, $6,9 \ldots$ The green contours denote regions of heat flux anomalies that exceed the $95 \%$ confidence level.
0 week

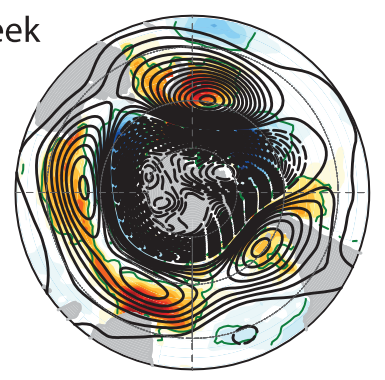

2 weeks

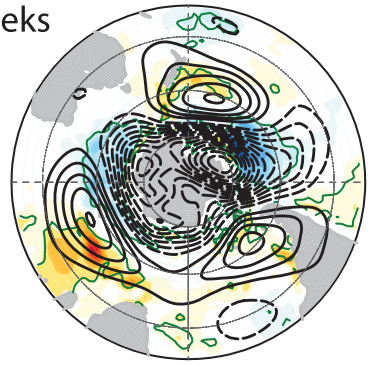

4 weeks

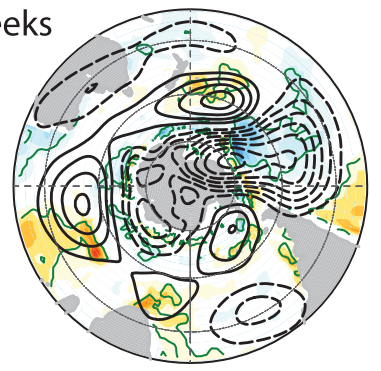

6 weeks

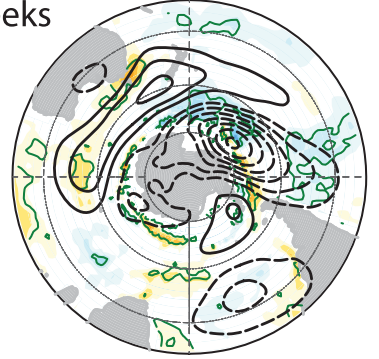

8 weeks

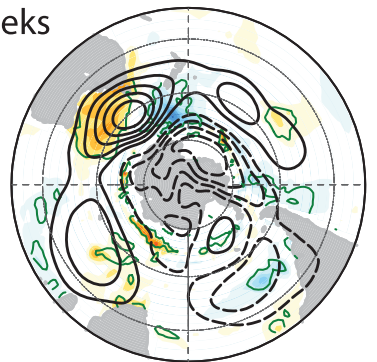

$\mathrm{Wm}-2$

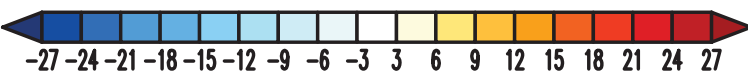

FIG. 9. As in Fig. 8, but regressions are based on the standardized SAM index. 


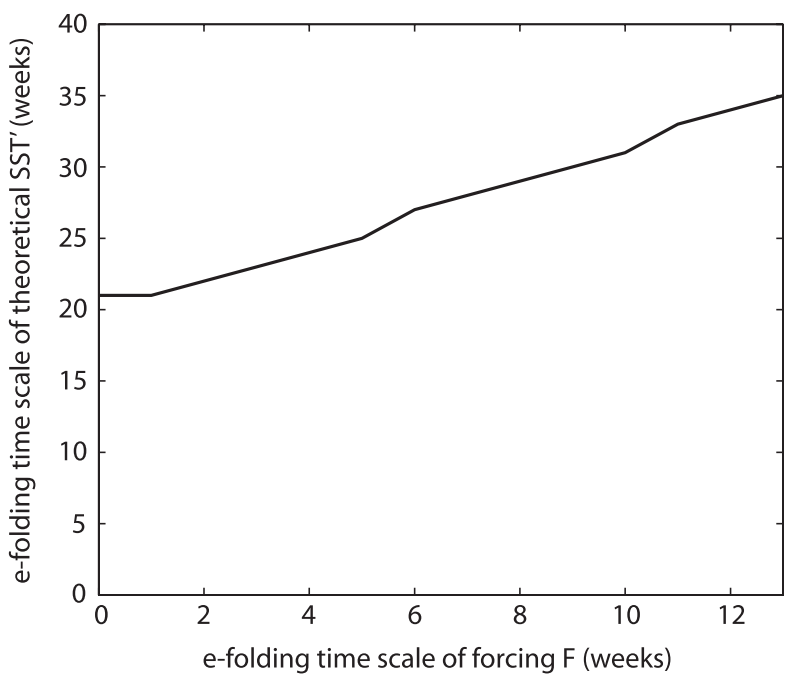

FIG. 10. Relationship between the $e$-folding time scale of $F$ constructed from a first-order Markov model [Eq. (4)] and the $e$-folding time scale of $T^{\prime}$ derived from Eq. (2) for $\rho=1000 \mathrm{~kg} \mathrm{~m}^{-3}$, $c_{p}=4218 \mathrm{~J} \mathrm{~kg}^{-1} \mathrm{~K}^{-1}, \lambda=25 \mathrm{~W} \mathrm{~m}{ }^{-2} \mathrm{~K}^{-1}$, and $H=100 \mathrm{~m}$.

the SST response. Thus, describing the SAM-related fluxes as white noise is a reasonable first-order approximation. Qualitatively similar results are obtained when the analysis in Fig. 10 is repeated using other realistic mixed layer depths.

2) The out-of-phase persistence of the NAM-related fluxes in turn decreases the persistence of the resulting NAM-related SST anomalies.

Figures 7 and 8 show that the North Atlantic surface turbulent and Ekman heat flux anomalies become negatively correlated with the NAM after 1-2 months, thereby acting in the opposite sense of the initial heat fluxes that generated the SST anomalies. It is possible that the NAM-related SST anomalies as well as the initial heat fluxes may be attenuated by the out-of-phase heat flux anomalies at a rate faster than if the out-of-phase heat fluxes were absent. These out-of-phase heat flux anomalies may arise as the result of a dynamic response of the forcing to the SST anomalies they created. As shown in several studies (Barsugli and Battisti 1998; Czaja et al. 2003; Lee et al. 2008), $F$ may be prescribed such that it contains both a white-noise component plus a net feedback of SSTs onto the atmospheric dynamics and can be expressed as

$$
F=N+(b-1) T^{\prime},
$$

where $N$ is the random white-noise component and $b$ is a real nondimensional constant that determines the degrees of feedback onto the forcing.

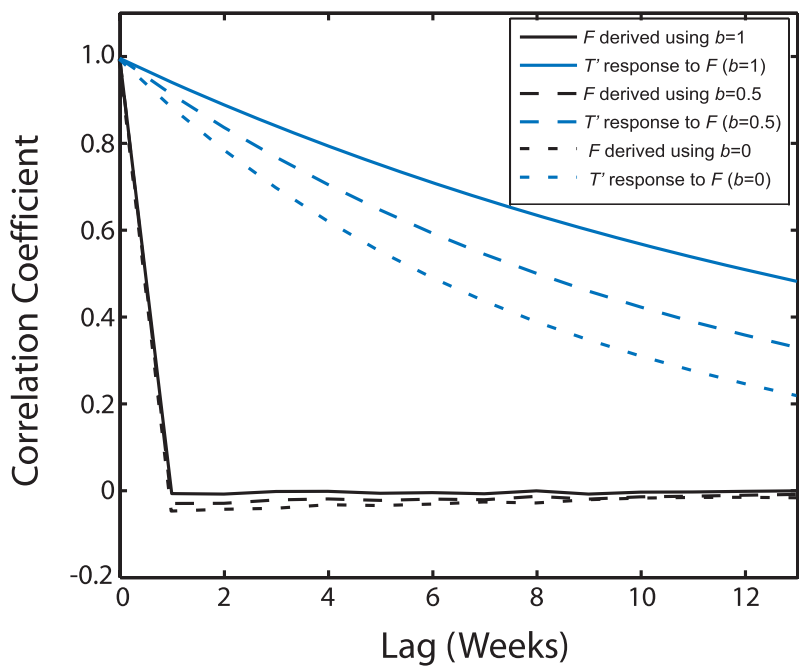

FIG. 11. Autocorrelation functions of $F$ (black curves) and $T^{\prime}$ (blue curves) derived from Eq. (2) and Eq. (5) for $\rho=1000 \mathrm{~kg} \mathrm{~m}^{-3}$, $c_{p}=4218 \mathrm{~J} \mathrm{~kg}^{-1} \mathrm{~K}^{-1}, \lambda=25 \mathrm{~W} \mathrm{~m}^{-2} \mathrm{~K}^{-1}$, and $H=65 \mathrm{~m}$; and $b=1$ (solid), $b=0.5$ (long dashed), and $b=0$ (short dashed).

Figure 11 shows the autocorrelation functions of $F$ and $T^{\prime}$ derived from Eqs. (5) and (2) using $H=65 \mathrm{~m}$, $\lambda=25 \mathrm{~W} \mathrm{~m}^{-2} \mathrm{~K}^{-1}$, and a range of values of $b$ from 0 to 1 as shown in Barsugli and Battisti (1998) and Lee et al. (2008). As expected, when no SST feedback onto $F$ exists $(b=1)$, the autocorrelation functions from the white-noise model are reproduced (i.e., compare the solid blue line in Fig. 11 with the dashed blue line in Fig. 3). Decreasing $b$ to 0 yields only a modest reduction in the autocorrelations of $F$, which become slightly negative; but the autocorrelations of $T^{\prime}$ have significantly decreased, now resembling that of the observed heat flux model or $\mathrm{SST}_{\mathrm{NAM}}$ (i.e., compare the short-dashed blue line in Fig. 11 with the dashed or solid blue lines in Fig. 4). The results in Fig. 11 suggest that the NAM-related heat fluxes cannot be approximated as white noise alone, but rather the forcing must also include the feedback from the underlying SST anomalies.

\section{Summary}

This study compares the large-scale extratropical SST variability between the North Atlantic and Southern Ocean basins, focusing on the persistence of these SST anomalies associated with the annular modes. The initial analysis reveals that during the warm season, observed North Atlantic SST anomalies associated with the NAM and Southern Ocean SST anomalies associated with the SAM exhibit similar degrees of persistence. In contrast, 
during the cold season, the $\mathrm{SST}_{\mathrm{NAM}}$ decays considerably faster than $\mathrm{SST}_{\mathrm{SAM}}$, which remains significantly correlated after 3 months. Possible mechanisms that could account for the observed differences in the persistence of cold-season SST anomalies were examined within the context of the simple stochastic climate paradigm proposed by FH77. In this idealized model, the tendency in SST anomalies is driven by an atmospheric forcing, characterized by surface turbulent and Ekman heat fluxes, damped back to atmospheric temperatures via surface turbulent heat fluxes and inversely proportional to the depth of the ocean mixed layer. We analyzed two formulations of the model outlined in FH77 to explore the persistence of extratropical SST anomalies: 1 ) the theoretical autocorrelations of $T^{\prime}$ were derived using mixed layer depths representative of the North Atlantic and Southern Ocean cold seasons, and the atmospheric forcing $F^{\prime}$ was modeled as a white-noise time series (i.e., the "white noise" model); and 2) the theoretical autocorrelations of $T^{\prime}$ were derived using the same mixed layer depths as in 1) but $F^{\prime}$ was defined as the observed surface turbulent and Ekman heat flux anomalies associated with the annular modes (i.e., the "observed heat flux" model).

In the Southern Ocean, the persistence of the observed cold-season SST $_{\text {SAM }}$ is well estimated by the simple climate model when the atmospheric forcing is approximated as white noise and the ocean mixed layer depth is taken to be the climatological mean cold-season value averaged across the Southern Ocean. Forcing the model with observed SAM-related turbulent and Ekman heat fluxes yields qualitatively similar results. Furthermore, changing the feedback parameter $\lambda$ had a relatively small effect on the theoretical autocorrelations. The autocorrelation analysis of the SAM-related total heat fluxes demonstrates that they exhibit significantly more memory than a white-noise process, but the fluxes do not significantly increase the persistence of the resulting SST anomalies. This suggests that prescribing the heat flux forcing of Southern Ocean SST anomalies as a whitenoise process is a reasonable first-order approximation. Similar results were obtained when the analysis is repeated over smaller area-averaged regions of the Southern Ocean, although the idealized FH77 model does not capture the observed cold-season SST persistence in the Indian Ocean.

In the North Atlantic, the average cold-season mixed layer depths are somewhat shallower than in the Southern Ocean; nevertheless, the white-noise model drastically overestimates the persistence of the NAM-related SST anomalies, suggesting that the forcing cannot be approximated by white noise alone. When the model is forced with the observed surface turbulent and Ekman heat fluxes associated with the NAM, the resulting theoretical autocorrelation function is more comparable to that of the observed cold-season $\mathrm{SST}_{\mathrm{NAM}}$. Analysis of the lagged relationship between the NAM and the associated heat fluxes reveals that the fluxes exhibit an out-of-phase pattern after 1-2 months, which may contribute to the accelerated damping of the NAM-related SST anomalies. There is some evidence to suggest that the evolution of the heat fluxes is consistent with temporal changes in the overlying circulation associated with the NAM/NAO. Changes in the atmospheric circulation could be an inherent feature of the NAM itself but could also arise from interactions with the Madden Julian oscillation (Cassou 2008), teleconnections from the Pacific (Honda et al. 2005), or influences from tropical Atlantic SST anomalies (e.g., Peng et al. 2005, 2006). However, the results in Fig. 11 also indicate that the persistence of $\mathrm{SST}_{\text {NAM }}$ is more accurately represented when the SST feedback is explicitly represented in the forcing.

This study has focused primarily on the cold season, when hemispheric differences in the persistence of annular mode-related SST anomalies are largest. In the warm season, stronger similarities are observed between the SST anomalies associated with the NAM and the SAM: both exhibit similar decorrelation time scales (Fig. 2) and nearly identical mixed layer depths $\left(H_{\mathrm{SO}}=\right.$ $40 \mathrm{~m}$ and $H_{\mathrm{NA}}=35 \mathrm{~m}$ ). In the North Atlantic, the warm-season SST-NAM relationship is considerably weaker than its cold-season counterpart; however, the autocorrelation function of the $\mathrm{SST}_{\mathrm{NAM}}$ can be reproduced by forcing the FH77 model with white noise, suggesting that the time scale of the warm-season $\mathrm{SST}_{\mathrm{NAM}}$ is primarily associated with the relatively shallow mixed layer observed during that time (not shown). A similar autocorrelation function is obtained when the FH77 model is forced with the observed NAM-related heat fluxes, which do not exhibit out-of-phase behavior; however, it should be noted that the NAM-related heat fluxes are not statistically significant at the $95 \%$ confidence level (not shown). In the Southern Ocean, the warm-season SAM-related SSTs are further impacted by ENSO, which in turn impacts the persistence of SSTs (Ciasto and Thompson 2008). If ENSO is removed from the $\mathrm{SST}_{\mathrm{SAM}}$ via linear regression on the Niño-3.4 index, then the observed autocorrelations appear to be well estimated when the FH77 model is forced by white noise or observed heat fluxes (not shown). However, a more thorough analysis is needed to adequately isolate the role of ENSO on the persistence of the warm-season SST $_{\text {SAM }}$.

In this study, we showed that a simple highly idealized model can be used to diagnose the mechanisms that govern the persistence of the annular-mode-related SST 
anomalies. However, other components of the upperocean mixed layer heat budget [Eq. (1)] not considered in this simple model can further impact the persistence of extratropical SST anomalies, including changes in the depth of the mixed layer, radiative heat fluxes, and advection by mean ocean currents. Our formulation of FH77 includes a fixed mixed layer depth, which does not allow for re-entrainment of SST anomalies because of deepening of the mixed layer during fall and early winter (Deser et al. 2003). This reemergence mechanism primarily impacts the persistence of SST anomalies from winter to winter, which is longer than the time scales examined in this study. However, entrainment of SST anomalies from the previous spring could affect the persistence of SST anomalies in the subsequent cold season, particularly if the re-entrained SST anomalies are out of phase with those initiated in the previous cold season. Future work should employ a full entraining model, which takes account of seasonally varying mixed layer depths as well as the explicit entrainment of SST anomalies from the previous spring.

Although radiative heat fluxes have been shown to impact the persistence of SST anomalies through positive feedbacks between SSTs and marine stratiform clouds (Namias et al. 1988; Park et al. 2006), the results of this study were unchanged when the annular-moderelated radiative heat fluxes were included in the forcing. The persistence of extratropical SST anomalies could also be influenced by non-Ekman advection (Frankignoul and Reynolds 1983; Herterich and Hasselmann 1987), particularly in regions of strong ocean currents, such as the Antarctic Circumpolar Current (ACC) and the Gulf Stream. These regions are impacted by the NAM and SAM but account for a relatively small fraction of the overall spatial scale of the annular modes. As a result, the FH77 model was able to reasonably simulate the observed $e$-folding time scales without including non-Ekman advection.

Our formulation of the FH77 model assumes a fixed damping parameter $\lambda$. The results of this study were not sensitive to a range of physical reasonable values of $\lambda$. However, the sensitivity of our results to changes in $\lambda$ over the course of the cold season was not explored, and it may be useful to consider in a future study. Some measurements of the spatial and temporal distribution of $\lambda$ have been made in the $\mathrm{NH}$ and equatorial oceans; however, at the present time, calculations of $\lambda$ in the Southern Ocean are limited (Park et al. 2005). It has also been suggested that $\lambda$ should also account for rapid (e.g., submonthly) variations in wind speed, which contributes to the damping (Sura et al. 2006; Sura and Newman 2008). These studies have also shown that splitting $\lambda$ into two components - a constant component and a stochastically varying component-can impact the time scales of the resulting SST variability.

Acknowledgments. We are would like to thank the editor and two anonymous reviewers for their constructive comments, which greatly improved the manuscript. We are also grateful to Dr. David Thompson for his helpful discussions of the results. L. Ciasto and M. H. England were supported by the Australian Research Council. M. Alexander was funded by NOAA's CLIVAR Program, and C. Deser gratefully acknowledges support from NCAR.

\section{REFERENCES}

Alexander, M. A., and C. Deser, 1995: A mechanism for the recurrence of wintertime midlatitude SST anomalies. J. Phys. Oceanogr., 25, 122-137.

, J. D. Scott, and C. Deser, 2000: Processes that influence sea surface temperature and ocean mixed layer depth variability in a coupled model. J. Geophys. Res., 105, 16823 16842 .

Ambaum, M. H. P., B. J. Hoskins, and D. B. Stephenson, 2001: Arctic Oscillation or North Atlantic Oscillation? J. Climate, 14, 3495-3507.

Barsugli, J. J., and D. S. Battisti, 1998: The basic effects of atmosphere-ocean thermal coupling on midlatitude variability. J. Atmos. Sci., 55, 477-493.

Bretherton, C. S., M. Widmann, V. P. Dymnikov, J. M. Wallace, and I. Bladé, 1999: The effective number of spatial degrees of freedom of a time-varying field. J. Climate, 12,19902009.

Cassou, C., 2008: Intraseasonal interaction between the MaddenJulian oscillation and the North Atlantic Oscillation. Nature, 455, 523-527.

, C. Deser, and M. A. Alexander, 2007: Investigating the impact of reemerging sea surface temperature anomalies on the winter atmospheric circulation over the North Atlantic. J. Climate, 20, 3510-3526.

Cayan, D. R., 1992a: Latent and sensible heat flux anomalies over the northern oceans: Driving the sea surface temperature. J. Phys. Oceanogr., 22, 859-881.

1992b: Latent and sensible heat flux anomalies over the northern oceans: The connection to monthly atmospheric circulation. J. Climate, 5, 354-369.

Ciasto, L. M., and D. W. J. Thompson, 2008: Observations of largescale ocean-atmosphere interaction in the Southern Hemisphere. J. Climate, 21, 1244-1259.

— , and — 2009: Observational evidence of reemergence in the extratropical Southern Hemisphere. J. Climate, 22, 14461453.

Czaja, A., A. Robertson, and T. Huck, 2003: The role of coupled processes in producing NAO variability. The North Atlantic Oscillation: Climatic Significance and Environmental Impact, Geophys. Monogr., Vol. 134, Amer. Geophys. Union, 147172.

da Silva, A. M., C. C. Young, and S. Levitus, 1994: Algorithms and Procedures. Vol. 1, Atlas of Surface Marine Data 1994, NOAA Atlas NESDIS 6, $83 \mathrm{pp}$ 
de Boyer Montégut, C., G. Madec, A. S. Fischer, A. Lazar, and D. Idicone, 2004: Mixed layer depth over the global ocean: An examination of profile data and a profile-based climatology. J. Geophys. Res., 109, C12003, doi:10.1029/ 2004JC002378.

de Coëtlogon, G., and C. Frankignoul, 2003: The persistence of winter sea surface temperature in the North Atlantic. J. Climate, 16, 1364-1377.

Deser, C., 2000: On the teleconnectivity of the "Arctic Oscillation." Geophys. Res. Lett., 27, 779-782.

, and M. S. Timlin, 1997: Atmosphere-ocean interaction on weekly timescales in the North Atlantic and Pacific. J. Climate, 10, 393-408.

— M. A. Alexander, and M. S. Timlin, 2003: Understanding the persistence of sea surface temperature anomalies in midlatitudes. J. Climate, 16, 57-72.

,-- S.-P. Xie, and A. S. Phillips, 2010: Sea surface temperature variability: Patterns and mechanisms. Annu. Rev. Mar. Sci., 2, 115-143.

Frankignoul, C., 1985: Sea surface temperature anomalies, planetary waves, and air-sea feedback in the middle latitudes. Rev. Geophys., 23, 357-390.

__ , and K. Hasselmann, 1977: Stochastic climate models. Part II: Application to sea-surface temperature variability and thermocline variability. Tellus, 29, 289-305.

_ mid-latitude sea surface temperature anomalies. J. Phys. Oceanogr., 13, 1131-1145.

— A. Czaja, and B. L'Heveder, 1998: Air-sea feedback in the North Atlantic and surface boundary conditions for ocean models. J. Climate, 11, 2310-2324.

Herterich, K., and K. Hasselmann, 1987: Extraction of mixed layer advection velocities, diffusion coefficients, feedback factors and atmospheric forcing parameters from the statistical analysis of North Pacific SST anomaly fields. J. Phys. Oceanogr., 17, 2145-2156.

Honda, M., Y. Kushnir, H. Nakamura, S. Yamane, and S. E. Zebiak, 2005: Formation, mechanisms, and predictability of the Aleutian-Icelandic low seesaw in ensemble AGCM simulations. J. Climate, 18, 1423-1434.

Hurrell, J. W., Y. Kushnir, M. Visbeck, and G. Ottersen, 2003: An overview of the North Atlantic Oscillation. The North Atlantic Oscillation: Climate Significance and Environmental Impact, Geophys. Monogr., Vol. 134, Amer. Geophys. Union, $1-35$.

Josey, S. A., 2001: A comparison of ECMWF, NCEP-NCAR, and SOC surface heat fluxes with moored buoy measurements in the subduction region of the northeast Atlantic. J. Climate, 14, 1780-1789.

- E. C. Kent, and P. K. Taylor, 1998: The Southampton Oceanography Centre (SOC) Ocean-Atmosphere heat, momentum and freshwater flux atlas. Southampton Oceanography Centre Rep. 6, 30 pp. [Available online at http://eprints. soton.ac.uk/19117/.]

Kalnay, E., and Coauthors, 1996: The NCEP/NCAR 40-Year Reanalysis Project. Bull. Amer. Meteor. Soc., 77, 437-471.

Lau, N.-C., and M. J. Nath, 1996: The role of the "atmospheric bridge" in linking tropical Pacific ENSO events to extratropical SST anomalies. J. Climate, 9, 2036-2057.

Lee, D. E., Z. Liu, and Y. Liu, 2008: Beyond thermal interaction between ocean and atmosphere: On the extratropical climate variability due to the wind-induced SST. J. Climate, 21, 20012018.
L'Heureux, M. L., and D. W. J. Thompson, 2006: Observed relationships between the El Niño-Southern Oscillation and the extratropical zonal-mean circulation. J. Climate, 19, 276287.

Luksch, U., 1996: Simulation of North Atlantic low-frequency SST variability. J. Climate, 9, 2083-2092.

Namias, J., and R. M. Born, 1970: Temporal coherence in North Pacific sea-surface temperature patterns. J. Geophys. Res., 75, 5952-5955.

— North Pacific sea surface temperatures. J. Geophys. Res., 79, 797-798.

_ _ X. Yuan, and D. R. Cayan, 1988: Persistence of North Pacific sea surface temperature and atmospheric flow patterns. J. Climate, 1, 682-703.

Norris, J. R., Y. Zhang, and J. M. Wallace, 1998: Role of low clouds in summertime atmosphere-ocean interactions over the North Pacific. J. Climate, 11, 2482-2490.

Park, S., C. Deser, and M. A. Alexander, 2005: Estimation of the surface heat flux response to sea surface temperature anomalies over the global oceans. J. Climate, 18, 4582-4599.

- M. A. Alexander, and C. Deser, 2006: The impact of cloud radiative feedback, remote ENSO forcing, and entrainment on the persistence of North Pacific sea surface temperature anomalies. J. Climate, 19, 6243-6261.

Peng, S., W. A. Robinson, S. Li, and M. P. Hoerling, 2005: Tropical Atlantic SST forcing of coupled North Atlantic seasonal responses. J. Climate, 18, 480-496.

$-, \ldots, \ldots$, and M. A. Alexander, 2006: Effects of Ekman transport on the NAO response to a tropical Atlantic SST anomaly. J. Climate, 19, 4803-4818.

Reynolds, R. W., N. A. Rayner, T. M. Smith, D. C. Stokes, and W. Wang, 2002: An improved in situ and satellite SST analysis for climate. J. Climate, 15, 1609-1625.

Screen, J. A., N. P. Gillett, A. Y. Karpechko, and D. P. Stevens, 2010: Mixed layer temperature response to the southern annular mode: Mechanisms and model representation. J. Climate, 23, 664-678.

Seager, R., Y. Kushnir, M. Visbeck, N. Naik, J. Miller, G. Krahmann, and H. Cullen, 2000: Causes of Atlantic Ocean climate variability between 1958 and 1998. J. Climate, 13, 2845-2862.

Sen Gupta, A., and M. H. England, 2006: Coupled oceanatmosphere-ice response to variations in the southern annular mode. J. Climate, 19, 4457-4486.

Smith, S. R., D. M. Legler, and K. V. Verzone, 2001: Quantifying uncertainties in NCEP reanalyses using high-quality research vessel observations. J. Climate, 14, 4062-4072.

Sura, P., and M. Newman, 2008: The impact of rapid wind variability upon air-sea thermal coupling. J. Climate, 21, 621637.

,-- , and M. A. Alexander, 2006: Daily to decadal sea surface temperature variability driven by state-dependent stochastic heat fluxes. J. Phys. Oceanogr., 36, 1940-1958.

Thompson, D. W. J., and J. M. Wallace, 2000: Annular modes in the extratropical circulation. Part I: Month-to-month variability. J. Climate, 13, 1000-1016.

Timlin, M. S., M. A. Alexander, and C. Deser, 2002: On the reemergence of North Atlantic SST anomalies. J. Climate, 15, 2707-2712.

Verdy, A., J. Marshall, and A. Czaja, 2006: Sea surface temperature variability along the path of the Antarctic Circumpolar Current. J. Phys. Oceanogr., 36, 1317-1331. 
Visbeck, M., E. P. Chassignet, R. G. Curry, T. L. Delworth, R. R. Dickson, and G. Krahmann, 2003: The ocean's response to North Atlantic Oscillation variability. The North Atlantic Oscillation: Climatic Significance and Environmental Impact, Geophys. Monogr., Vol. 134, Amer. Geophys. Union, 113146.

Wallace, J. M., and D. W. J. Thompson, 2002: The Pacific center of action of the Northern Hemisphere annular mode: Real or artifact? J. Climate, 15, 1987-1991.
Watanabe, M., and M. Kimoto, 2000: On the persistence of decadal SST anomalies in the North Atlantic. J. Climate, 13, 30173028.

Yu, L., R. A. Weller, and B. Sun, 2004: Mean and variability of the WHOI daily latent and sensible heat fluxes at in situ flux measurement sites in the Atlantic Ocean. J. Climate, 17, 2096-2118.

Zhang, Y., J. R. Norris, and J. M. Wallace, 1998: Seasonality of large-scale atmosphere-ocean interaction over the North Pacific. J. Climate, 11, 2473-2481. 